Original Research Article

\title{
An overview of ecohydrology of the Yellow River delta wetland
}

\author{
Hua Zhang*, Xiaobing Chen, Yongming Luo \\ Key Laboratory of Coastal Zone Environmental Processes and Ecological Remediation, Yantai Institute of Coastal Zone Research, Chinese \\ Academy of Sciences, Yantai, Shandong, China
}

\section{A R T I C L E I N F O}

\section{Article history:}

Received 1 April 2015

Received in revised form 15 September 2015

Accepted 13 October 2015

Available online 6 November 2015

\section{Keywords:}

Yellow River

Water-sediment regulation

Delta

Sediment load

Coastline

\begin{abstract}
A B S T R A C T
The combined effects of geophysical and ecological processes, such as water and sediment load, land use change, eustatic sea level rise, land subsidence, and wetland loss, have produced a dynamic eco-hydrologic environment of the Yellow River delta (YRD) in northern China. Recent changes due to socio-economic forces and climate change have threatened the status of YRD wetland as important habitats of endangered species of wild birds and hatchery of aquatic animals on the brink of extinction. This review demonstrates that water-sediment regulation scheme (WSRS) in the last 10 years has brought some ecological benefits to the wetlands, but more recent observations have indicated diminishing effectiveness of the engineering projects. Although research has been conducted to monitor, evaluate, and predict the ecological and hydrological conditions of the YRD, tremendous knowledge gaps still exist for the sustainable management of the YRD for multiple objectives of natural reserve, energy extraction, and agricultural production. Therefore, ecologists and hydrologists should work together with social scientists and policy makers to develop a holistic plan that not only maintains the ecological integrity but also improves the livelihood of people in the YRD.
\end{abstract}

(C) 2015 European Regional Centre for Ecohydrology of the Polish Academy of Sciences. Published by Elsevier Sp. z o.o. All rights reserved.

\section{Introduction}

The Yellow River delta (YRD) in northern China has received increasing attention from scientists, engineers, and environmental planners because of its critical role in wildlife protection, energy production, and agriculture. The YRD has the largest and youngest coastal wetland ecosystem in China, providing habitat for millions of wild birds and serving as spawning and nursery grounds for numerous freshwater and marine organisms (Cui et al., 2009; Kong et al., 2015; Ma et al., 2014). In addition, tremendous values of ecosystem services including

\footnotetext{
* Corresponding author. Tel.: +86 15275534495

E-mail address: hzhang@yic.ac.cn (H. Zhang).
}

nutrient cycling, carbon storage, as well as tourism and recreation are provided by the YRD wetlands (Yu et al., 2011, 2012). Economically, YRD has the second largest oil field in China and the energy production and related industrial activities have caused enormous impact on the surface and subsurface environment in the region (Kuenzer et al., 2014). Agricultural production has occupied a large fraction of the newly formed delta lands and utilized substantial amount of riverine and underground freshwater resources (Han et al., 2014; Xu et al., 2002).

Like many of the large deltas around the world (Blum and Roberts, 2009; Syvitski et al., 2009), the YRD is facing increasing risks of degradation due to anthropogenic and natural forces (Bi et al., 2014; Cui et al., 2009; Gao et al., 2014; Kong et al., 2015; Wang et al., 2007). The fundamental changes in land-building and land loss in 
the YRD plain are rooted in the supply of water and sediment from Yellow River that undergone major shifts in the river's course since the delta's formation in 1855 . Superimposed on the natural processes, population growth, oil and gas extraction, and agricultural development have placed enormous demands on the land and water resources and modified the delta's natural geologic, hydrologic, and ecologic systems. Furthermore, global climate change and sea level rise has modified ecohydrological processes within the delta and the effect is expected to intensify in the future (Wang et al., 2006). The objective of this article is to identify the knowledge gaps and future research needs of wetland ecohydrology in YRD based on a comprehensive review of literature.

\section{A changing ecohydrological environment of YRD wetland}

Several comprehensive overviews of the historical development of the YRD has been conducted in the last few decades (Li et al., 1998b; Liu et al., 2004; Saito et al., 2001; Xue, 1993; Yu et al., 2011). Briefly, the Yellow River is the second largest river in China with a total drainage area of $794,712 \mathrm{~km}^{2}$ and a total length of $5464 \mathrm{~km}$ (Bi et al., 2014). As shown in Fig. 1, the river originates from the Tibet Plateau and flows through Loess Plateau and the North China Plain. The Yellow River has carried tremendous amount of sediments both to the northeast Bohai Sea and to the southeast Yellow Sea during the Holocene (Zhou et al., 2014). The modern YRD has formed since the mouth of the Yellow River shifted north in year 1855. The tremendous sediment load from the Yellow River has resulted in a complex deltaic environment. In the last 160 years, the main channel of the Yellow River has shifted courses 11 times and has built out a series of deltaic wedges into the nearby Bohai Sea. Collectively, sediment deposition at the mouth of Yellow River have produced eight overlaid distributary lobes with the active lobe developing around the Qingshuigou channels formed in 1976. The delta plain covers an area of $7870 \mathrm{~km}^{2}$ with average deposition thickness around $15 \mathrm{~m}$ (Bornhold et al., 1986; Wang et al., 2012). The hydrodynamics near Yellow River mouth is dominated by semidiurnal tides (tidal range around $1.5-2.0 \mathrm{~m}$ ) and wind driven waves and residual currents (Bi et al., 2014). For the groundwater system of YRD, Gao et al. (2014) divided coastal wetlands into groundwater seepage zone, tidal-induced transitional zone, and tidal zone, where the influence radius of oceanic tide is approximately $12-18 \mathrm{~km}$. Integrated study on the interaction between freshwater inflow, sea water, and groundwater is urgently needed for the understanding of the hydrological processes of the YRD wetland.

With annual average rainfall of $590.9 \mathrm{~mm}$ and potential evaporation of $1962 \mathrm{~mm}$, the YRD has a typical water limited environment where water resources need to be supplemented by river discharge and groundwater extraction (Kong et al., 2015; Newman et al., 2006). Over the past 60 years, construction of hydraulic structures and dramatic landuse changes in the Yellow River watershed has converted the second longest river in China to a hydrologic system highly regulated by human activities ( $\mathrm{Li}$ et al., 1998a). Hydrological circle of the Yellow River Delta (YRD) has undergone a series of regime shift, characterized by 70-90\% reductions in water and sediment supply (Wang et al., 2007; Yu et al., 2013), which is similar to many other large deltaic systems in the world (Blum and Roberts, 2009; Syvitski et al., 2009). The downward trends in runoff were also caused by climate change and increased water consumption in the Yellow River Basin (Xu, 2003). The downstream Yellow River experienced serious drying up events from 1991 to 1999 with a maximum of 226 no flow days in 1997. Since 2002, watershed scale water-sediment regulation scheme (WSRS) was operated annually by the Yellow River Conservancy Committee (YRCC) with the objective of restoring ecohydrological conditions downstream (YRCC, 2014). During the period of WSRS operation (around 15-20 days), approximately $28 \%$ of the river runoff and $57 \%$ of sediment load was rapidly discharged through controlled release from the Xiaolangdi Reservoir. This abrupt change of flow and sediment pattern has caused substantial change of the morphological patterns (Bi et al., 2014; Wang et al., 2010) and landscape patterns (Li et al., 2009) of the YRD. However, the dynamic biological and ecological response of YRD wetlands to water and sediment discharge pattern were not adequately studied due to the lack of long term monitoring data and welldesigned experiments (Sun et al., 2010).

Sea level rise (SLR) due to global change and land subsidence caused by extraction of groundwater and hydrocarbon has further jeopardized the health of YRD. In year 2012, the eustatic mean sea level (MSL) of the Bohai Sea has risen to $110 \mathrm{~mm}$ above the historical level (China Sea Level Bulletin, 2012). The MSL of Bohai Sea has shown an accelerated rising trend with a mean linear rate of $3.8 \mathrm{~mm} /$ year, which is higher than the global and national average. It is projected that the mean sea level of the Bohai Sea will rise another $68-140 \mathrm{~mm}$ by 2040 (Pelling et al., 2013). Rates of land subsidence in the modern YRD might exceed the rates of sea level rise due to natural compaction and consolidation, urban construction, underground water and brine withdrawal, and oil extraction (Higgins et al., 2013; Zhang et al., 2015). The results of InSAR time series analysis revealed the spatial pattern of widespread land subsidence in the modern YRD and reported an average subsidence rate of $-5.1 \mathrm{~mm} /$ year (Zhang et al., 2015). Subsidence rates as high as $250 \mathrm{~mm} /$ year has been observed in selected areas and extraction of deep groundwater has been recognized as the dominant cause. The comprehensive study of Syvitski et al. (2009) has listed YRD as a delta in greater peril with a relative sea level rise of 8-23 mm/year due to sediment load reduction, sea level rise, and land subsidence. It shows that $1430 \mathrm{~km}^{2}$ of the YRD is under threat of storm surge. As relative sea level rising much faster than delta-plain construction, the YRD has already experienced significant erosion and the overall area of YRD decreased since year 2000 (Kong et al., 2015). A series of engineering structures including dikes, levees, groins, and roads were built along the coast of YRD to protect agricultural and industrial facilities (Zhang et al., 2015). Those engineering construction were the main factor that slowed down the coastal erosion of YRD. However, concrete construction has severely altered 
a

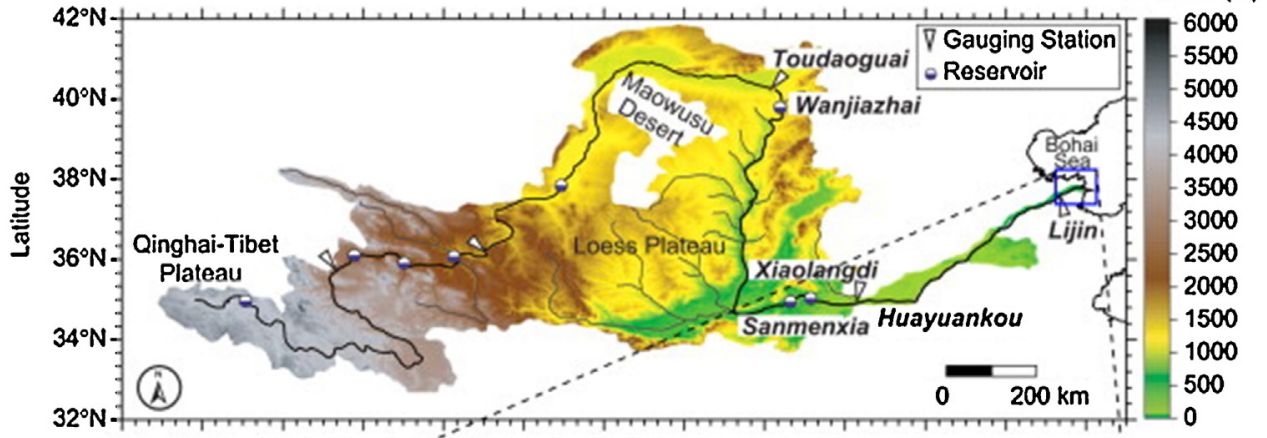

$95^{\circ} \mathrm{E} \quad 97^{\circ} \mathrm{E} \quad 99^{\circ} \mathrm{E} \quad 101^{\circ} \mathrm{E}, 103^{\circ} \mathrm{E} 105^{\circ} \mathrm{E} 107^{\circ} \mathrm{E} 109^{\circ} \mathrm{E} 111^{\circ} \mathrm{E} 113^{\circ} \mathrm{E} 115^{\circ} \mathrm{E} 117^{\circ} \mathrm{E} 119^{\circ} \mathrm{E}$

b

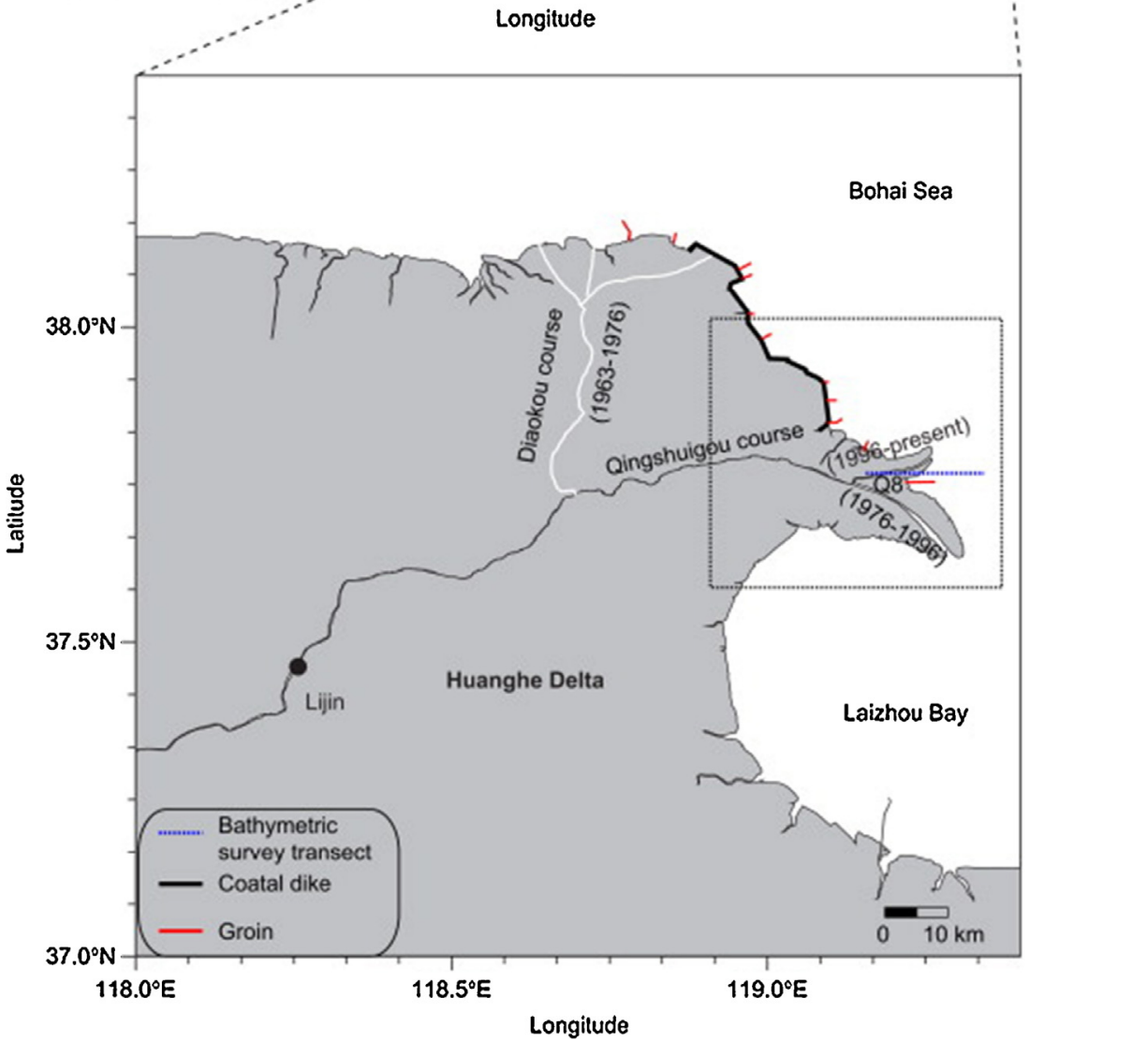

Fig. 1. (a) Map of the Yellow River drainage basin, showing the locations of major gauging stations and reservoirs in the main stream. The Yellow River is divided into the upper, middle and lower reaches by the Toudaoguai and Huayuankou gauges. (b) Map of the Yellow River delta showing the migration of the Yellow River deltaic river channel since 1976. The dashed rectangle in panel (b) indicates the location of the active Yellow River delta lobe.

Reproduced with permission from Bi et al. (2014).

hydrologic cycle and may cause substantial negative impact to biodiversity and associated ecosystem functions (Gao et al., 2014). Systematic studies are urgently required to study the hydrological evolution of YRD wetland driven by sea level rise, land subsidence, and coastal construction.

\section{Wetland degradation and restoration}

The YRD wetland supports abundant biodiversity and is home to 220 seed plant species such as endangered wild soybean (Glycine soja Siebold \& Zucc.), more than 800 wild animal species, and 283 bird species, many of which are listed as endangered species (Cui et al., 2009). It provides an important habitat and transfer area for millions of migrating birds, such as the red-crowned crane, hooded crane, Siberian crane, oriental stork, black stork, and golden eagle (Wang et al., 2014; Xu et al., 2002). It is reported that wetlands covered an area of $4167 \mathrm{~km}^{2}$ in YRD (Fig. 2), including $3131 \mathrm{~km}^{2}$ of natural wetlands (swamps, marshes, tidal mudflats, rivers, lakes, etc.) and $1036 \mathrm{~km}^{2}$ of artificial wetlands (rice fields, aquaculture ponds, channels, et al.) (Qi and Luo, 2007). The predominant native 


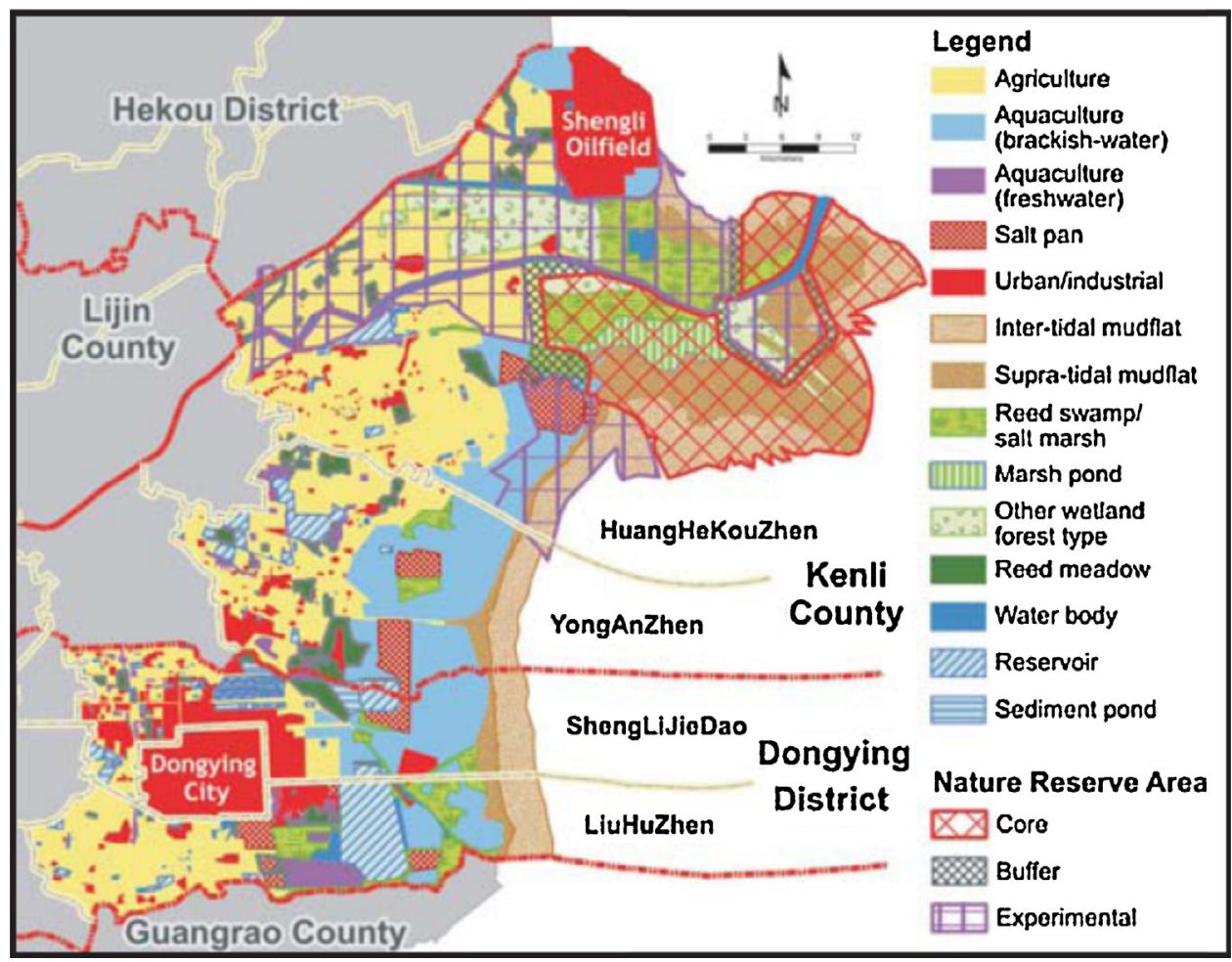

Fig. 2. Land use map showing the distribution and types of wetlands in the Yellow River delta.

Reproduced from the WorldFish Center (2010).

vegetation are salt tolerant plants and aquatic plants including Suaeda salsa, Phragmites australis, Tamarix chinensis Lour., Aeluropus sinenis and Imperata cylindrica (Linn.) Beauv (He et al., 2007). A frequent succession among vegetation communities exists in the newly created wetlands (Yue et al., 2003). Soils of the YRD wetland are classified as Calcaric Fluvisols, Gleyic Solonchaks and Salic Fluvisols according to Food and Agriculture Organization (FAO) system and often have high salinity, low nutrient content and low organic matter (Yu et al., 2014). The vegetation type and soil properties (e.g., salinity, organic matter) often demonstrate a spatial pattern that can be related to the distance to the Yellow River course and the gradient from sea to land (Li et al., 2009; Yu et al., 2014, 2012). Soil salinity increased and organic content decreased in some areas owing to improper cultivation on lands that are not suitable for crop production (Xu et al., 2002; Yu et al., 2012). In addition, elevated concentrations of heavy metals, polycyclic aromatic hydrocarbons (PAHs), petroleum hydrocarbons, and pesticides have been observed in soil and plant samples, potentially caused by energy and chemical industries (Li et al., 2014; Yuan et al., 2014; Zhu et al., 2015). Overall, the ecological evolution of this newly created wetland and its interaction with climate and hydrology were not well understood due to the scarcity of long term monitoring data of the soils, plants, and animals.

The wetland ecosystem is seriously stressed due to depleting water resources, degradation of soil quality, water pollution, and agricultural and industrial activities in the YRD. The reed marsh, meadow, and tidal wetland decreased by $17 \%, 37 \%$, and 38\%, respectively, from 1986 to 2001 due to decreased runoff and sediment load and conversion to aquacultural ponds and agricultural fields ( $\mathrm{Li}$ et al., 2009). Construction of oil wells and roads has decreased landscape patch connectivity (Yue et al., 2003). As a result, the areas of red-crowned crane habitat decreased by 5935 ha from 1992 to 2008 (Wang et al., 2014). In addition, coastal construction and aquaculture activities might have destroyed the habitat of many wild species of aquatic organisms. Despite the lack of monitoring data, circumstantial evidences show that there are severe decreases in bird populations, sharp decrease in indigenous plant communities accompanied by increasing population of invasive species.

Wetland restoration projects have been initiated since the start of new millennium in order to prevent the wetlands from further deterioration and to protect endangered birds (Cui et al., 2009; Wang et al., 2014; Yang, 2011). Through WSRS operation, freshwater totaling $1.0 \times 10^{8} \mathrm{~m}^{3}$ have been allocated from Yellow River to the wetlands through a set of reservoirs and channels in July or August to ensure the supplement of sediment. Dikes have been constructed along the seashore to prevent seawater intrusion. The freshwater replenishment had significantly improved the structure and function of wetland ecosystem as indicated by rising water table, improving soil quality, increasing plant cover, and return of migrating and breeding birds by 2007 (Cui et al., 2009). However, recent surveys suggest that operations at current level may not be sufficient to fully 
restore the plant and bird communities. A systematic review and assessment of the management practices of the YRD wetlands is urgently needed before further degradation of the ecosystem health (YRCC, 2013).

\section{Concluding remarks and outlook}

Although large amounts of researches have been conducted to study the evolution of YRD and its wetland ecosystem, this review of recent literatures shows that tremendous knowledge gaps still exist on the dynamics of ecohydrology of YRD wetland, especially the impacts of large scale anthropogenic activities including oil and gas production, agricultural development, as well as sediment and water regulation. From the ecohydrological prospective, we recommend to carry out following studies: (1) Interaction between river flow, sea water, and groundwater analyzed through in situ monitoring and modeling; (2) Biological and ecological response of wetlands to different water and sediment regimes studied by well-designed plot experiments; (3) Ecosystem health assessment based on comprehensive field data of water, soils, plants, birds, and aquatic organisms; (4) Future projection of the change of YRD wetland system due to climate changes and anthropogenic forces. However, it should be emphasized that the current issues in YRD wetlands are deeply connected with the regional socio-economic status. Competition for limited land and water resources by industrialization and urbanization has become the dominant stressor of the wetland ecosystem. Therefore, a cross-disciplinary discussion and policy development is essential to restore ecological integrity and improve livelihood of people in YRD.

\section{Conflict of interest}

None declared.

\section{Ethical statement}

Authors state that the research was conducted according to ethical standards.

\section{Funding body}

This work was supported by National Natural Science Foundation of China (41271506, 41230858) and Key Research Program of Chinese Academy of Sciences (KZZDEW-14), and the State Key Laboratory of Soil and Sustainable Agriculture (Institute of Soil Science, Chinese Academy of Sciences). Dr. Hua Zhang was supported by the Recruitment Program of Global Young Experts (1000Plan).

\section{Acknowledgments}

This work was supported by National Natural Science Foundation of China (41271506, 41230858) and Key Research Program of Chinese Academy of Sciences (KZZD-EW-14), and the State Key Laboratory of Soil and Sustainable Agriculture (Institute of Soil Science, Chinese
Academy of Sciences). Dr. Hua Zhang was supported by the Recruitment Program of Global Young Experts (1000Plan).

\section{References}

Bi, N., Wang, H., Yang, Z., 2014. Recent changes in the erosion-accretion patterns of the active Huanghe (Yellow River) delta lobe caused by human activities. Cont. Shelf Res. 90, 70-78.

Blum, M.D., Roberts, H.H., 2009. Drowning of the Mississippi Delta due to insufficient sediment supply and global sea-level rise. Nat. Geosci. 2, 488-491.

Bornhold, B.D., Yang, Z.S., Keller, G.H., Prior, D.B., Wiseman, W.J., Wang, Q., Wright, L.D., Xu, W.D., Zhuang, Z.Y., 1986. Sedimentary framework of the modern Huanghe (Yellow-River) Delta. Geo-Mar. Lett. 6, 77-83.

Cui, B., Yang, O., Yang, Z., Zhang, K., 2009. Evaluating the ecological performance of wetland restoration in the Yellow River Delta, China. Ecol. Eng. 35, 1090-1103.

Gao, M., Liu, S., Zhao, G., Yuan, H., Wei, C., Wu, Y., Tang, J., 2014. Vulnerability of eco-hydrological environment in the Yellow River Delta wetland. J. Coast. Res. 30, 344-350.

Han, G., Xing, Q., Yu, J., Luo, Y., Li, D., Yang, L., Wang, G., Mao, P., Xie, B. Mikle, N., 2014. Agricultural reclamation effects on ecosystem $\mathrm{CO}_{2}$ exchange of a coastal wetland in the Yellow River Delta. Agric. Ecosyst. Environ. 196, 187-198.

He, Q., Cui, B., Zhao, X., Fu, H., Xiong, X., Feng, G., 2007. Vegetation distribution patterns to the gradients of water depth and soil salinity in wetlands of Yellow River Delta, China. Wetland Sci. 5, 208-214.

Higgins, S., Overeem, I., Tanaka, A., Syvitski, J.P.M., 2013. Land subsidence at aquaculture facilities in the Yellow River delta, China. Geophys. Res. Lett. 40, 3898-3902.

Kong, D., Miao, C., Borthwick, A.G.L., Duan, Q., Liu, H., Sun, Q., Ye, A., Di, Z., Gong, W., 2015. Evolution of the Yellow River Delta and its relationship with runoff and sediment load from 1983 to 2011. J. Hydrol. 520, 157-167.

Kuenzer, C., Ottinger, M., Liu, G., Sun, B., Baumhauer, R., Dech, S., 2014. Earth observation-based coastal zone monitoring of the Yellow River Delta: dynamics in China's second largest oil producing region over four decades. Appl. Geogr. 55, 92-107.

Li, G.X., Wei, H.L., Han, Y.S., Chen, Y.J., 1998a. Sedimentation in the Yellow River delta, part I: flow and suspended sediment structure in the upper distributary and the estuary. Mar. Geol. 149, 93-111.

Li, G.X., Wei, H.L., Yue, S.H., Cheng, Y.J., Han, Y.S., 1998b. Sedimentation in the Yellow River delta, part II: suspended sediment dispersal and deposition on the subaqueous delta. Mar. Geol. 149, 113-131.

Li, S.-N., Wang, G.-X., Deng, W., Hu, Y.-M., Hu, W.-W., 2009. Influence of hydrology process on wetland landscape pattern: a case study in the Yellow River Delta. Ecol. Eng. 35, 1719-1726.

Li, Y., Zhang, H.B., Chen, X.B., Tu, C., Luo, Y.M., Christie, P., 2014. Distribution of heavy metals in soils of the Yellow River Delta: concentrations in different soil horizons and source identification. J. Soils Sediments 14, 1158-1168.

Liu, J.P., Milliman, J.D., Gao, S., Cheng, P., 2004. Holocene development of the Yellow River subaqueous delta, North Yellow Sea. Mar. Geol. 209, 45-67.

Ma, Z., Melville, D.S., Liu, J., Chen, Y., Yang, H., Ren, W., Zhang, Z., Piersma, T., Li, B., 2014. Rethinking China's new great wall. Science 346, 912-914.

Newman, B.D., Wilcox, B.P., Archer, S.R., Breshears, D.D., Dahm, C.N., Duffy, C.J., McDowell, N.G., Phillips, F.M., Scanlon, B.R., Vivoni, E.R., 2006. Ecohydrology of water-limited environments: a scientific vision. Water Resour. Res. 42.

Pelling, H.E., Uehara, K., Green, J.A.M., 2013. The impact of rapid coastline changes and sea level rise on the tides in the Bohai Sea, China. J. Geophys. Res.: Oceans 118, 3462-3472.

Qi, S., Luo, F., 2007. Environmental degradation in the Yellow River Delta, Shandong Province, China. Ambio 36, 610-611.

Saito, Y., Yang, Z.S., Hori, K., 2001. The Huanghe (Yellow River) and Changjiang (Yangtze River) deltas: a review on their characteristics, evolution and sediment discharge during the Holocene. Geomorphology $41,219-231$.

State Oceanic Administration (SOA), 2015. China Sea Level Bulletin. State Oceanic Administration.

Sun, Z., Mou, X., Lin, G., Wang, L., Song, H., Jiang, H., 2010. Effects of sediment burial disturbance on seedling survival and growth of Suaeda salsa in the tidal wetland of the Yellow River estuary. Plant Soil 337, 457-468.

Syvitski, J.P.M., Kettner, A.J., Overeem, I., Hutton, E.W.H., Hannon, M.T., Brakenridge, G.R., Day, J., Vorosmarty, C., Saito, Y., Giosan, L., Nicholls, R.J., 2009. Sinking deltas due to human activities. Nat. Geosci. 2, 681-686. 
The WorldFish Center, 2010. Wetlands of the Yellow River Delta: A Heritage to Conserve and Treasure. Issues Brief no. 2107. The WorldFish Center, Penang, Malaysia, pp. 6.

Wang, H., Yang, Z., Saito, Y., Liu, J.P., Sun, X., 2006. Interannual and seasonal variation of the Huanghe (Yellow River) water discharge over the past 50 years: connections to impacts from ENSO events and dams. Global Planet. Change 50, 212-225.

Wang, H., Yang, Z., Saito, Y., Liu, J.P., Sun, X., Wang, Y., 2007. Stepwise decreases of the Huanghe (Yellow River) sediment load (1950-2005): Impacts of climate change and human activities. Global Planet. Change 57, 331-354

Wang, H., Bi, N., Saito, Y., Wang, Y., Sun, X., Zhang, J., Yang, Z., 2010. Recent changes in sediment delivery by the Huanghe (Yellow River) to the sea: causes and environmental implications in its estuary. J. Hydrol. 391, 302-313.

Wang, M., Qi, S., Zhang, X., 2012. Wetland loss and degradation in the Yellow River Delta, Shandong Province of China. Environ. Earth Sci. 67, 185-188.

Wang, H., Gao, J., Pu, R.L., Ren, L.L., Kong, Y., Li, H., Li, L., 2014. Natural and anthropogenic influences on a red-crowned crane habitat in the Yellow River Delta Natural Reserve, 1992-2008. Environ. Monit. Assess. 186, 4013-4028.

Xu, J.X., 2003. Sediment flux to the sea as influenced by changing human activities and precipitation: example of the Yellow River, China. Environ. Manag. 31, 328-341.

Xu, X., Guo, H., Chen, X., Lin, H., Du, Q., 2002. A multi-scale study on land use and land cover quality change: the case of the Yellow River Delta in China. GeoJournal 56, 177-183.

Xue, C.T., 1993. Historical changes in the Yellow-River Delta, China. Mar Geol. 113, 321-330.

Yang, W., 2011. A multi-objective optimization approach to allocate environmental flows to the artificially restored wetlands of China's Yellow River Delta. Ecol. Model. 222, 261-267.

Yellow River Conservancy Commission (YRCC), 2013. Comprehensive plan of the Yellow River watershed (2012-2030). Yellow River Conservancy Press, Zhengzhou.
Yellow River Conservancy Commission (YRCC), 2014. Yellow River Sediment Bulletin. Yellow River Conservancy Press, Zhengzhou.

Yu, J., Fu, Y., Li, Y., Han, G., Wang, Y., Zhou, D., Sun, W., Gao, Y., Meixner, F.X., 2011. Effects of water discharge and sediment load on evolution of modern Yellow River Delta, China, over the period from 1976 to 2009. Biogeosciences 8, 2427-2435.

Yu, J., Wang, Y., Li, Y., Dong, H., Zhou, D., Han, G., Wu, H., Wang, G., Mao, P., Gao, Y., 2012. Soil organic carbon storage changes in coastal wetlands of the modern Yellow River Delta from 2000 to 2009. Biogeosciences 9, 2325-2331.

Yu, Y., Wang, H., Shi, X., Ran, X., Cui, T., Qiao, S., Liu, Y., 2013. New discharge regime of the Huanghe (Yellow River): causes and implications. Cont. Shelf Res. 69, 62-72.

Yu, J., Li, Y., Han, G., Zhou, D., Fu, Y., Guan, B., Wang, G., Ning, K., Wu, H., Wang, J., 2014. The spatial distribution characteristics of soil salinity in coastal zone of the Yellow River Delta. Environ. Earth Sci. 72, 589-599.

Yuan, H.M., Li, T.G., Ding, X.G., Zhao, G.M., Ye, S.Y., 2014. Distribution, sources and potential toxicological significance of polycyclic aromatic hydrocarbons (PAHs) in surface soils of the Yellow River Delta, China. Mar. Pollut. Bull. 83, 258-264.

Yue, T.X., Liu, J.Y., Jorgensen, S.E., Ye, Q.H., 2003. Landscape change detection of the newly created wetland in Yellow River Delta. Ecol. Model. 164, 21-31.

Zhang, J.-Z., Huang, H.-J., Bi, H.-B., 2015. Land subsidence in the modern Yellow River Delta based on InSAR time series analysis. Nat. Hazards 75, 2385-2397.

Zhou, L., Liu, J., Saito, Y., Liu, J.P., Li, G., Liu, Q., Gao, M., Qiu, J., 2014. Fluvial system development and subsequent marine transgression in Yellow River (Huanghe) delta and its adjacent sea regions during last glacial maximum to early Holocene. Cont. Shelf Res. 90, 117-132.

Zhu, L.H., Wang, Y.J., Jiang, L.H., Lai, L.M., Ding, J.Z., Liu, N.X., Li, J.S., Xiao, N.W., Zheng, Y.R., Rimmington, G.M., 2015. Effects of residual hydrocarbons on the reed community after 10 years of oil extraction and the effectiveness of different biological indicators for the long-term risk assessments. Ecol. Indic. 48, 235-243. 